NASA/TM-2002-211812

\title{
Single Axis Attitude Control and DC Bus Regulation With Two Flywheels
}

Peter E. Kascak and Ralph H. Jansen

University of Toledo, Toledo, Ohio

Barbara Kenny

Glenn Research Center, Cleveland, Ohio

Timothy P. Dever

QSS Group, Inc., Cleveland, Ohio 
Since its founding, NASA has been dedicated to the advancement of aeronautics and space science. The NASA Scientific and Technical Information (STI) Program Office plays a key part in helping NASA maintain this important role.

The NASA STI Program Office is operated by Langley Research Center, the Lead Center for NASA's scientific and technical information. The NASA STI Program Office provides access to the NASA STI Database, the largest collection of aeronautical and space science STI in the world. The Program Office is also NASA's institutional mechanism for disseminating the results of its research and development activities. These results are published by NASA in the NASA STI Report Series, which includes the following report types:

- $\quad$ TECHNICAL PUBLICATION. Reports of completed research or a major significant phase of research that present the results of NASA programs and include extensive data or theoretical analysis. Includes compilations of significant scientific and technical data and information deemed to be of continuing reference value. NASA's counterpart of peerreviewed formal professional papers but has less stringent limitations on manuscript length and extent of graphic presentations.

- TECHNICAL MEMORANDUM. Scientific and technical findings that are preliminary or of specialized interest, e.g., quick release reports, working papers, and bibliographies that contain minimal annotation. Does not contain extensive analysis.

- CONTRACTOR REPORT. Scientific and technical findings by NASA-sponsored contractors and grantees.
- CONFERENCE PUBLICATION. Collected papers from scientific and technical conferences, symposia, seminars, or other meetings sponsored or cosponsored by NASA.

- SPECIAL PUBLICATION. Scientific, technical, or historical information from NASA programs, projects, and missions, often concerned with subjects having substantial public interest.

- TECHNICAL TRANSLATION. Englishlanguage translations of foreign scientific and technical material pertinent to NASA's mission.

Specialized services that complement the STI Program Office's diverse offerings include creating custom thesauri, building customized databases, organizing and publishing research results ... even providing videos.

For more information about the NASA STI Program Office, see the following:

- Access the NASA STI Program Home Page at http://www.sti.nasa.gov

- E-mail your question via the Internet to help@sti.nasa.gov

- Fax your question to the NASA Access Help Desk at 301-621-0134

- Telephone the NASA Access Help Desk at 301-621-0390

- Write to:

NASA Access Help Desk

NASA Center for AeroSpace Information 7121 Standard Drive

Hanover, MD 21076 
NASA/TM-2002-211812

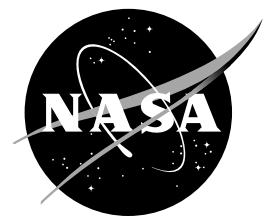

\section{Single Axis Attitude Control and DC Bus Regulation With Two Flywheels}

Peter E. Kascak and Ralph H. Jansen

University of Toledo, Toledo, Ohio

Barbara Kenny

Glenn Research Center, Cleveland, Ohio

Timothy P. Dever

QSS Group, Inc., Cleveland, Ohio

Prepared for the

37th Intersociety Energy Conversion Engineering Conference

sponsored by the Institute of Electrical and Electronics Engineers, Electron Devices Society

Washington, DC, June 28-August 2, 2002

National Aeronautics and

Space Administration

Glenn Research Center 
Available from

NASA Center for Aerospace Information 7121 Standard Drive

Hanover, MD 21076
National Technical Information Service 5285 Port Royal Road Springfield, VA 22100

Available electronically at http://gltrs.grc.nasa.gov 


\title{
Single Axis Attitude Control and DC Bus Regulation With Two Flywheels
}

\author{
Peter E. Kascak and Ralph H. Jansen \\ University of Toledo \\ Toledo, Ohio 43606 \\ 216-433-8408, peter.e.kascak@grc.nasa.gov \\ 216-433-6038, ralph.h.jansen@grc.nasa.gov \\ Barbara Kenny \\ National Aeronautics and Space Administration \\ Glenn Research Center \\ Cleveland, Ohio 44135 \\ 216-433-6289, barbara.h.kenny@grc.nasa.gov \\ Timothy P. Dever \\ QSS Group, Inc. \\ Cleveland, Ohio 44135 \\ 216-433-2384, timothy.p.dever@grc.nasa.gov
}

\begin{abstract}
A computer simulation of a flywheel energy storage single axis attitude control system is described. The simulation models hardware which will be experimentally tested in the future. This hardware consists of two counter rotating flywheels mounted to an airtable. The airtable allows one axis of rotational motion. An inertia DC bus coordinator is set forth that allows the two control problems, bus regulation and attitude control, to be separated. Simulation results are presented with a previously derived flywheel bus regulator (Kascak, 2001) and a simple PID attitude controller.
\end{abstract}

\section{INTRODUCTION}

Flywheel system and technology development work has been an ongoing activity at NASA Glenn

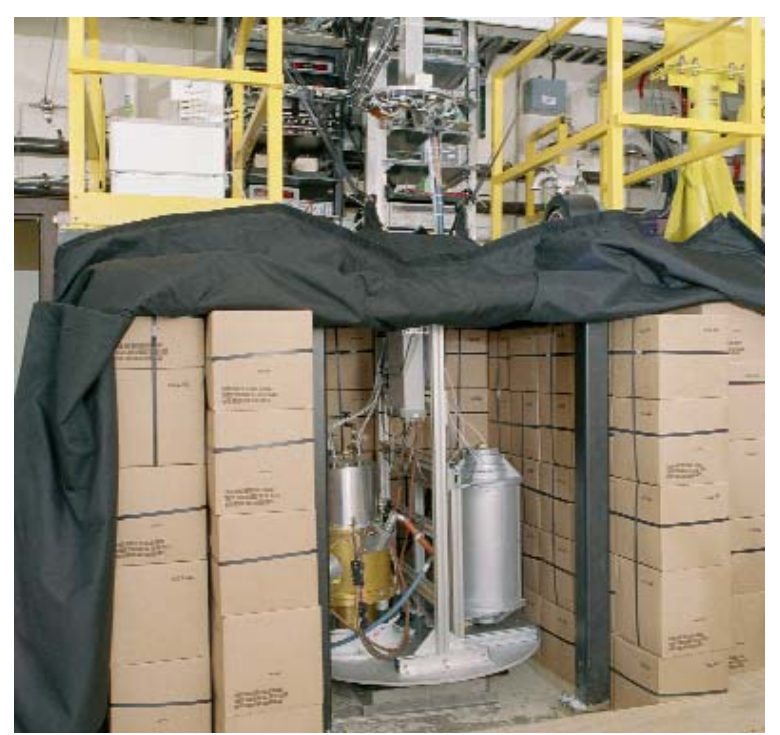

FIGURE 1 - HIGH ENERGY FLYWHEEL FACILITY
Research Center over the past several years. Most recently, work has been conducted under the Aerospace Flywheel Technology Program (AFT) and the Flywheel Energy Storage System Program (FESS). This paper discusses simulation results of a control algorithm for combined power bus regulation and single degree of freedom torque and momentum control using a two flywheel system. A discussion of related programs sponsored by NASA and the US Air Force has been done. (McLallin, 2001).

The algorithm presented will be experimentally verified in the Attitude Control and Energy Storage Experiment Phase 0 (ACESE_0). In this experiment two technology demonstrator flywheel modules developed under FESS and a previous flight program will be integrated at NASA GRC's High Energy Flywheel Facility (HEFF). Figure 1 shows the facility which consists of an airtable where the modules are

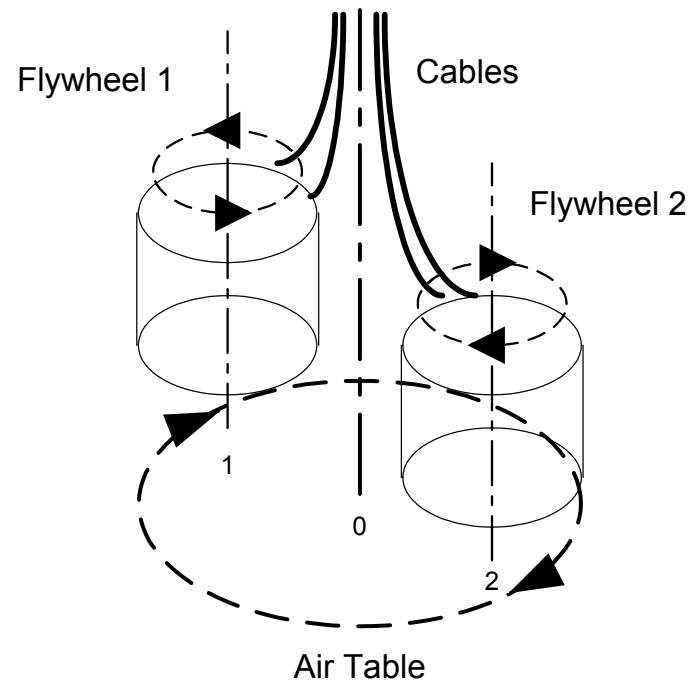

FIGURE 2 - HIGH ENERGY FLYWHEEL FACILITY SCHEMATIC 
mounted surrounded by a water containment safety system (Trase 2002). Thermal, vacuum, and instrumentation support hardware can be seen on the upper platform. A simple schematic of the setup is shown in Figure 2. The experiment will be a hardware demonstration of a flywheel system which provides both power bus regulation and a single axis torque and attitude control. The long term objective is to extend this work to a bus regulation and three degree of freedom attitude control system representative of a satellite platform.

\section{NOMENCLATURE}

$I_{D C}$ - DC current provided by flywheel system (A)

$I_{D C, m}$ - DC current into flywheel inverter m (A)

$I_{P / S}$ - DC current out of the power supply (A)

$J_{x}$ - moment of inertia about axis $\mathrm{x}\left(\mathrm{kg}^{*} \mathrm{~m}^{2}\right)$

$L_{d}$ - direct axis self inductance $(\mathrm{H})$

$L_{q}$ - quadrature axis self inductance $(\mathrm{H})$

$p$ - derivative operator

$P$ - number of poles

$T_{d}$ - disturbance torque $\left(\mathrm{N}^{*} \mathrm{~m}\right)$

$T_{e}$ - electromagnetic torque $\left(\mathrm{N}^{*} \mathrm{~m}\right)$

$T_{p}$ - platform torque $\left(\mathrm{N}^{*} \mathrm{~m}\right)$

$V_{D C}$ - DC bus Voltage (V)

$\lambda_{a f}$ - mutual flux linkages by rotor magnets, $\left(\mathrm{V}^{*} \mathrm{~s}\right)$

$\omega_{r 2}-$ electrical frequency $(\mathrm{rad} / \mathrm{s})$

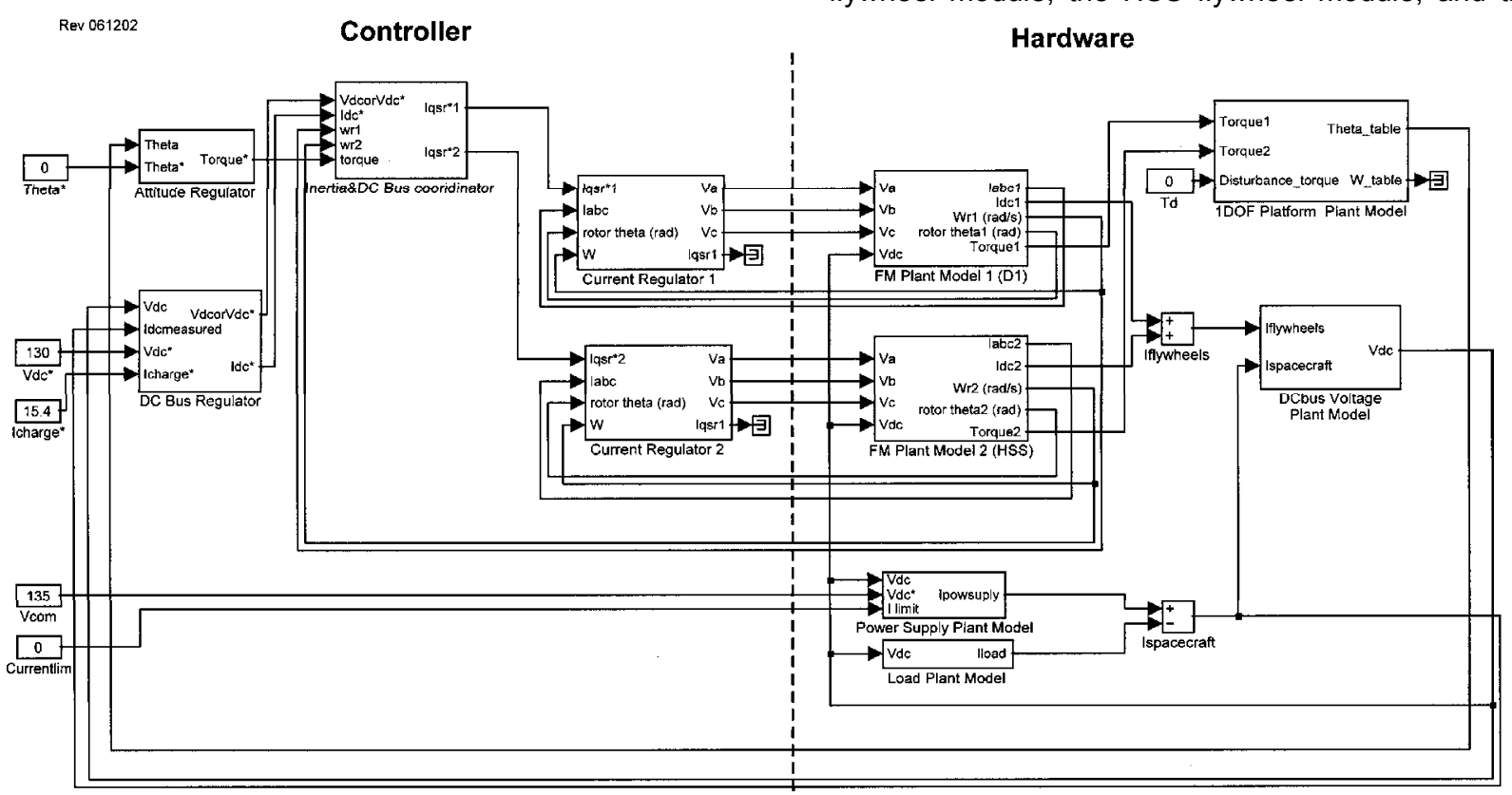

FIGURE 3 - SYS'TEM MODEL

\section{SYSTEM MODEL}

The ACESE_0 simulation is divided into two parts, the controllers and the plant models (Figure 3 ). Each controller regulates progressively higher level states as we move from the inner to outer control loop. Plant models are provided for each hardware subcomponent. The model does not include switching effects, motor torque ripple, or other higher order effects that are required to estimate power or torque quality. The purpose of the model is to develop a functional controller for the hardware demonstration.

Plant models were developed for the two flywheel modules, a single degree of freedom platform mounted on an airtable, a power supply, an electrical load, and the DC bus.

The controller has two nested loops and a coordinator. The innermost loop is a motor current regulator for each flywheel. The outer loop has a DC bus regulation algorithm and attitude control algorithm operating simultaneously. The system level commands of bus voltage and pointing angle get issued to the highest level loop. The coordinator parses the demands from the bus regulator and attitude controller into current commands for each flywheel module.

Inputs to the system controllers include: $V_{D C}^{*}$, $I_{\text {charge }}^{*}$ (to DC Bus regulator) and theta ${ }^{*}$ (to attitude regulator). The parameters that are varied are: $V_{\text {com }}$, $I_{\text {limit }}$ (power supply plant model), load resistance (load plant model), and disturbance torque (platform plant model).

\section{Mechanical Plant Models}

The flywheel modules which will be incorporated into HEFF are called D1 and HSS. The mechanical plant models included in the system are the D1 flywheel module, the HSS flywheel module, and the

Hardware 
single degree of freedom plant model.

The D1 Flywheel Module (D1) and the High Speed Shaft (HSS) flywheel module used in this test are not identical, however they both have generally the same topology. They each have magnetically suspended rotors with permanent magnet motor/generators, mechanical touchdown bearings, and an integral housing/vacuum enclosure. Table 1 contains the flywheel module properties.

The mechanical system is modeled as a single degree of freedom second order system. The airtable and all the components mounted on it other than the flywheel rotors will be referred to as the platform. The platform components are modeled as inertias about the spin axis of air table. These components are the base, avionics, and flywheel stator assemblies. The flywheel rotors are included as torques acting on the platform. Figure 4 shows a free body diagram of the system. Axes 0,1 , and 2 represent the rotation axes of the platform, flywheel 1, and flywheel 2 respectively. The equation of motion for the platform is:

$$
J \ddot{\theta}_{0}+c \dot{\theta}_{0}+k \theta_{0}=\sum T
$$

The work in this paper does not include platform damping and stiffness effects; these are set to zero in the model. The terms are included for future modeling of the cable harness stiffness and bearing damping in the experimental hardware.

The total inertia about the 0 axis, $J_{0}$, is the sum of the inertia of the base, avionics, flywheel stator assemblies and flywheel rotors.

$$
\begin{aligned}
J_{0}= & J_{a}+J_{b}+ \\
& \left(J_{r 1}+m_{r 1} x_{1}^{2}\right)+\left(J_{s 1}+m_{s 1} x_{1}^{2}\right) \\
& \left(J_{r 2}+m_{r 2} x_{2}^{2}\right)+\left(J_{s 2}+m_{s 2} x_{2}^{2}\right)
\end{aligned}
$$

The base and avionics are modeled as circular cylinders. The flywheel stators are considered circular cylindrical shells located on a parallel axis. The flywheel rotors are circular cylinders on parallel axis. The standard equations are applied (Meriam and Kraige, 1986).

$$
J_{z z}=\frac{1}{2} m r^{2} \quad \text { circular cylinder }
$$

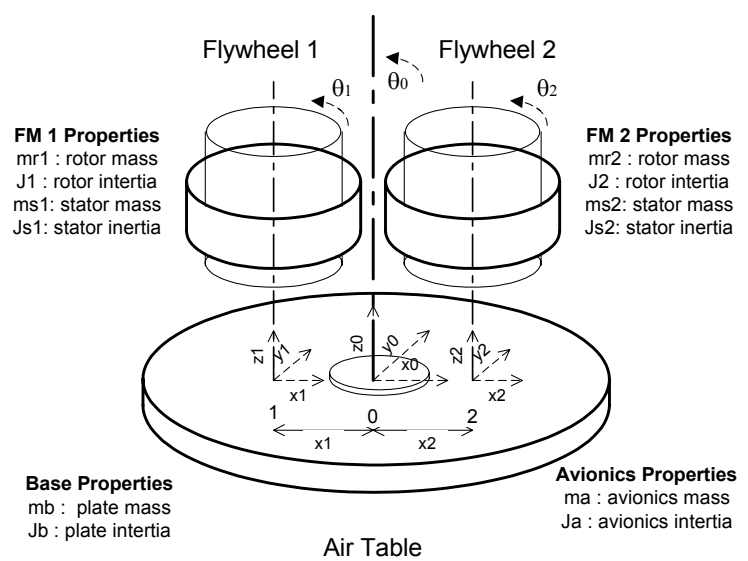

FIGURE 4 - FREE BODY DIAGRAM

$$
\begin{array}{r}
J_{z z}=m r^{2} \text { circular cylindrical shell } \\
J_{\text {axis_a }}=J_{a x i s_{-} b}+m d_{a_{-} t t_{-} b}{ }^{2} \text { parallel axis }
\end{array}
$$

The torques applied to the platform are equal and opposite to the torque applied to the rotors of each flywheel model. Resultant torques from rotor translation are neglected. The platform inertia reacts to the sum of the torques.

$$
\sum T=T_{p}=-T_{e 1}-T_{e 2}
$$

The flywheel module is modeled as a single degree of freedom rotor with a torque applied by the motor/generator. The motor is modeled as a synchronous permanent magnet machine (Krishnan, 1996).

\begin{tabular}{|c|c|c|}
\hline & Value & Property \\
\hline \multicolumn{3}{|c|}{ System } \\
\hline$J_{0}$ & $25.22 \mathrm{~kg} \cdot \mathrm{m}^{2}$ & platform inertia about axis 0 \\
\hline c & 0 & platform damping \\
\hline $\mathrm{k}$ & 0 & platform stiffness \\
\hline \multicolumn{3}{|c|}{ D1 Flywheel Module } \\
\hline$m_{r 1}$ & $17.2 \mathrm{~kg}$ & rotor mass \\
\hline$J_{r 1}$ & $0.0664 \mathrm{~kg} \cdot \mathrm{m}^{2}$ & rotor polar moment of inertia \\
\hline$m_{s 1}$ & $61.2 \mathrm{~kg}$ & stator mass \\
\hline $\mathrm{J}_{\mathrm{s} 1}$ & $560 \mathrm{~kg} \cdot \mathrm{m}^{2}$ & $\begin{array}{l}\text { stator polar moment of } \\
\text { inertia }\end{array}$ \\
\hline$\overline{x_{1}}$ & $0.254 \mathrm{~m}$ & distance from axis 0 to 1 \\
\hline $\mathrm{L}_{q 1}$ & $0.000025 \mathrm{H}$ & $q$ axis inductance of motor \\
\hline $\mathrm{L}_{\mathrm{d} 1}$ & $0.000019 \mathrm{H}$ & $\mathrm{d}$ axis inductance of motor \\
\hline $\mathrm{R}_{\mathrm{s} 1}$ & $0.0145 \Omega$ & I-n stator resistance of motor \\
\hline$\lambda_{\text {af1 }}$ & $0.00733 \mathrm{~V}-\mathrm{s}$ & rotor magnet flux linkage \\
\hline $\mathrm{B}_{1}$ & 0 & viscous drag on rotor \\
\hline \multicolumn{3}{|c|}{ HSS Flywheel Module } \\
\hline $\mathrm{m}_{\mathrm{r} 2}$ & $6.53 \mathrm{~kg}$ & rotor mass \\
\hline$J_{\mathrm{r} 2}$ & $0.00377 \mathrm{~kg} \cdot \mathrm{m}^{2}$ & rotor polar moment of inertia \\
\hline $\mathrm{m}_{\mathrm{s} 2}$ & $56.7 \mathrm{~kg}$ & stator mass \\
\hline $\mathrm{J}_{\mathrm{s} 2}$ & $518 \mathrm{~kg} \cdot \mathrm{m}^{2}$ & $\begin{array}{l}\text { stator polar moment of } \\
\text { inertia }\end{array}$ \\
\hline$x_{2}$ & $0.254 \mathrm{~m}$ & distance from axis 0 to 1 \\
\hline $\mathrm{L}_{\mathrm{q} 2}$ & $0.000142 \mathrm{H}$ & $\mathrm{q}$ axis inductance of motor \\
\hline $\mathrm{L}_{\mathrm{q} 2}$ & $0.000101 \mathrm{H}$ & $\mathrm{d}$ axis inductance of motor \\
\hline $\mathrm{R}_{\mathrm{s} 2}$ & $0.035 \Omega$ & I-n stator resistance of motor \\
\hline$\lambda_{\mathrm{af} 2}$ & $0.014456 \mathrm{~V}-\mathrm{s}$ & rotor magnet flux linkage \\
\hline $\mathrm{B}_{2}$ & 0 & viscous drag on rotor \\
\hline \multicolumn{3}{|l|}{ Base } \\
\hline$m_{b}$ & $40.1 \mathrm{~kg}$ & base mass \\
\hline$J_{b}$ & $2939 \mathrm{~kg} \cdot \mathrm{m}^{2}$ & base polar moment of inertia \\
\hline \multicolumn{3}{|c|}{ Avionics } \\
\hline$m_{a}$ & $40.1 \mathrm{~kg}$ & avionics mass \\
\hline$J_{a}$ & $2939 \mathrm{~kg} \cdot \mathrm{m}^{2}$ & $\begin{array}{l}\text { avionics polar moment of } \\
\text { inertia }\end{array}$ \\
\hline C & $5860 \mu \mathrm{F}$ & dc bus capacitance \\
\hline
\end{tabular}

\section{Electrical Plant Models}

The electrical model includes: the DC bus voltage plant model, the power supply plant model, and the load plant model.

The DC bus is modeled as a capacitor with various current sources charging or discharging it

TABLE 1 - SYSTEM PROPERTIES 
(Figure 5). These currents are the inputs to the DC bus model and consist of: the DC currents provided by the flywheels $\left(I_{D C 1}+I_{D C 2}\right)$, the power supply current $\left(I_{P / S}\right)$, and the load current $\left(I_{\text {load }}\right)$.

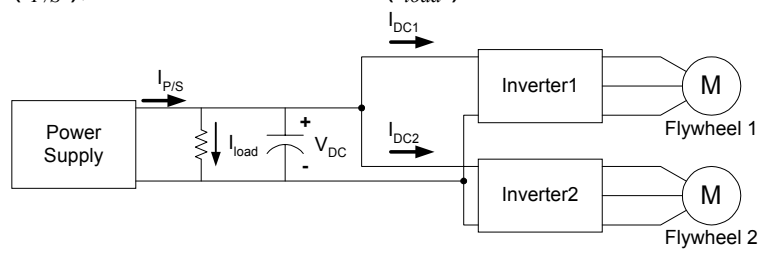

FIGURE 5 - DC BUS MODEL

The power supply is modeled as a voltage regulating current source. The power supply model has two inputs, one for a voltage setpoint and one for a current limit. The power supply will provide whatever current, $I_{P / S}$, is necessary to keep the bus voltage at the voltage setpoint as long as the current is less than the current limit. To accomplish this in the model the error between the voltage setpoint and the bus voltage is taken. This error is run through a $\mathrm{PI}$ control law to provide a current command. This current command is compared to the current limit. If the command is less than the current limit, $I_{P / S}$ is equal to the current command. If the current command is greater than the current limit, $I_{P / S}$ is equal to the current limit.

The load is modeled as a resistor. Thus the current consumed by the load is just the DC bus voltage divided by the value of the resistor.

\section{Controller Model}

The controller model includes: a current regulator for each flywheel, a DC bus regulator, an attitude regulator, and an inertia and DC bus coordinator (Figure3).

The two motors are controlled by field orientation, with back emf voltage decoupling (Krishnan 1999). The d-axis rotational reference frame current is commanded to zero and the q-axis rotational reference frame current command varies to provide attitude control and bus regulation. A detailed description of the innerloop controller, albeit without voltage decoupling, can be found in Kenny (2001).

There are three modes of DC bus regulation: charge, charge reduction, and discharge. The charge mode represents operation in full sun when the photovoltaics system provides current and voltage regulation. In the charge mode the $\mathrm{DC}$ bus regulator charges the flywheel system at the charge setpoint $\left(I_{\text {charge }}^{*}\right)$ The charge reduction mode represents operation in partial sun when the current generated by the photovoltaics system is not sufficient to meet both the load demand and the flywheel charge setpoint. During this mode of operation the flywheel system regulates the DC bus voltage to $V_{d c}^{*}$. The discharge mode represents operation in eclipse when the photovoltaics system provides less current than required by the load. In both charge reduction mode and discharge mode the $\mathrm{DC}$ bus regulation algorithm uses the DC current from each of the two flywheel inverters to regulate the bus voltage. More detail on the DC bus regulator and the modes of operation can be found in Kascak (2001).

The q-axis rotational reference frame current commands to the two flywheel motor controllers, $i^{{ }^{*} r}{ }_{q s l}$ and $i^{{ }^{*}}{ }_{q s 2}$, provide both attitude control and DC bus regulation. The first relationship necessary to determine the appropriate current commands is the power balance. The AC power in one of the flywheel motors can be expressed as shown in Novotny et. al (1996).

$$
P_{\text {flywheel }}=\frac{3}{2}\left(v_{q s}^{r} i_{q s}^{r}+v_{d s}^{r} i_{d s}^{r}\right)
$$

Exploiting the fact that the d-axis current is regulated to zero and equating the $A C$ and $D C$ power, the following is obtained where $I_{D C, m}$ is the DC current into one of the flywheel motor inverters.

$$
V_{D C} I_{D C, m}=\frac{3}{2}\left(v_{q s}^{r} i_{q s}^{r}\right)
$$

The q-axis voltage equation is (Krishnan, 1999)

$$
v_{q s}^{r}=i_{q s}^{r} R_{s}+L_{q s} p i_{q s}^{r}+i_{d s}^{r} \omega_{r} L_{d s}+\omega_{r} \lambda_{a f}
$$

In steady state the derivative term goes to zero. Also the d-axis current is regulated to zero. Finally the resistive term is much smaller than the back emf term especially at high speeds, thus we have (Kascak 2001),

$$
V_{D C} I_{D C, m} \approx \frac{3}{2}\left(\omega_{r} \lambda_{a f} i_{q s}^{r}\right)
$$

Equation (11) expresses the DC current in terms of the rotational reference frame q-axis current, $i_{q s}^{r}$, with a dependence on a motor constant, $\lambda_{a f}$, the rotor speed, $\omega_{r}$, and the DC bus voltage $V_{D C}$.

$$
I_{D C, m} \approx \frac{3 \omega_{r} \lambda_{a f}}{2 V_{D C}} i_{q s}^{r}
$$

The total DC bus current, $I_{D C}$, is the sum of the two motor inverter DC currents, $I_{D C 1}$ and $I_{D C 2}$. This can be expressed as shown in (12) in terms of the rotational reference frame q-axis current, $i_{q s}^{r}$, for each motor.

$$
\begin{gathered}
I_{D C}=c i_{q s 1}^{r}+d i_{q s 2}^{r} \\
c=\frac{3 \omega_{r 1} \lambda_{a f 1}}{2 V_{D C}} \\
d=\frac{3 \omega_{r 2} \lambda_{a f 2}}{2 V_{D C}}
\end{gathered}
$$

The torque applied to the platform is equal and opposite to the torque applied to the rotor. The expression for torque produced by the flywheel PM motors is given as (Krishnan, 1999) :

$$
T_{e}=\frac{3}{2} \frac{P}{2}\left[\lambda_{a f}+\left(L_{d}-L_{q}\right) i_{d s}^{r}\right] i_{q s}^{r}
$$


However the rotational reference frame d-axis current is controlled to be zero. Thus the torque can be expressed as:

$$
T_{e}=\frac{3}{2} \frac{P}{2} \lambda_{a f} i_{q s}^{r}
$$

The total torque that is applied to the platform is the negative sum of the two motor torques, $T_{e 1}$ and $T_{e 2}$. This is expressed (from 6) as:

$$
\begin{gathered}
T_{p}=-T_{e 1}-T_{e 2}=-a i_{q s 1}^{r}-b i_{q s 2}^{r} \\
a=\frac{3}{2} \frac{P_{1}}{2} \lambda_{a f 1} \\
b=\frac{3}{2} \frac{P_{2}}{2} \lambda_{a f 2}
\end{gathered}
$$

By solving equations (12) and (17) simultaneously, the control variables $i_{q s 1}^{r}$ and $i_{q s 2}^{r}$ can be found which provide the desired DC bus current, $I_{D C}$, and the platform torque, $T_{p}$. The result is given in equations (20) and (21).

$$
\begin{gathered}
i_{q s 1}^{r}=\frac{b I_{D C}+d T_{p}}{c b-d a} \\
i_{q s 2}^{r}=\frac{T_{p}+a i_{q s 1}^{r}}{-b}
\end{gathered}
$$

Thus the required values of $i_{q s 1}^{r}$ and $i_{q s 2}^{r}$ to provide the desired amount of DC current and the desired amount of torque to the platform are found.

\section{RESULTS}

System model simulations were run for three different test cases: DC bus regulation throughout mode transitions with a constant platform angle, platform angle and DC bus response to a step change in commanded angle with a constant electrical load, and the system response to a step change in disturbance torque. Commanded variable and system parameter settings for each of these simulations are summarized in Table 2.

\section{Bus Regulation}

\begin{tabular}{|c|c|c|c|c|}
\hline & \multicolumn{2}{|c|}{ Commanded Values } & \multicolumn{2}{|c|}{ Bus Condition } \\
\hline Test & $\begin{array}{c}\text { Bus } \\
\text { Regulator }\end{array}$ & $\begin{array}{c}\text { Attitude } \\
\text { Regulator }\end{array}$ & $\begin{array}{l}\text { Power } \\
\text { Supply }\end{array}$ & Load \\
\hline $\begin{array}{l}\text { DC Bus } \\
\text { Regulation }\end{array}$ & $\begin{array}{l}V_{D C}^{*}=130 \\
I_{\text {charge }}^{*}=15.4\end{array}$ & $\begin{array}{l}\text { theta }^{*}=0 \\
T_{d}=0\end{array}$ & $\begin{array}{l}6-0 \mathrm{~kW} \\
\text { ramp }\end{array}$ & $2 \mathrm{~kW}$ \\
\hline $\begin{array}{l}\text { Angle } \\
\text { Regulation }\end{array}$ & $\begin{array}{l}V_{D C}^{*}=130 \\
I_{\text {charge }}^{*}=15.4\end{array}$ & $\begin{array}{l}\text { theta }^{*}= \\
1.0^{\circ} \text { step } \\
T_{d}=0\end{array}$ & $0 \mathrm{~kW}$ & $\tilde{\mathrm{kW}} 0$ \\
\hline $\begin{array}{l}\text { Torque } \\
\text { Disturbance } \\
\text { Rejection }\end{array}$ & $\begin{array}{l}V_{D C}^{*}=130 \\
I_{\text {charge }}^{*}=15.4\end{array}$ & $\begin{array}{l}\text { theta }^{*}=0 \\
T_{d}=0.05 \\
\text { N-m step }\end{array}$ & $0 \mathrm{~kW}$ & $\tilde{\mathrm{kW}}^{0} 0$ \\
\hline
\end{tabular}

This simulation verifies that the controller maintains DC bus voltage regulation and platform angle regulation as the system transitions through all three modes of operation: charge, charge reduction, and

\section{TABLE 2 - SIMULATION PARAMETERS}

discharge. The mode transitions were achieved by starting the model in charge mode with the power supply current limit set to maximum (from $t=0$ to $t=1$ sec.), then decreasing the limit linearly to zero (from $t=1$ to $t=3$ sec.). This represents the spacecraft moving out of full sun and into eclipse.

While examining bus performance, it is helpful to refer to (22), which is derived from Figure 5:

$$
I_{\text {load }}=I_{P / S}-I_{D C l}-I_{D C 2}
$$

Power modes for this simulation are displayed in Figure 6. For the first second of the simulation, the system is in charge mode; the power supply regulates the bus voltage. The dc bus voltage is held at 135 volts by the power supply. The two flywheel units are being charged at $I_{D C 1}$ and $I_{D C 2}$ respectively where $I_{D C I}$ $+I_{D C 2}=I_{\text {charge }}^{*}$.

At $t=1$ second, the system transitions into charge reduction mode as the power supply current limit is reduced. At this point the sum of the load current, $I_{\text {load }}$, and the commanded charge current, $I_{\text {charge, }}^{*}$ is greater than the amount of current the power supply can provide and the power supply can no longer regulate the bus voltage. The flywheel system takes over bus regulation, as can be seen by the drop in $V_{D C}$

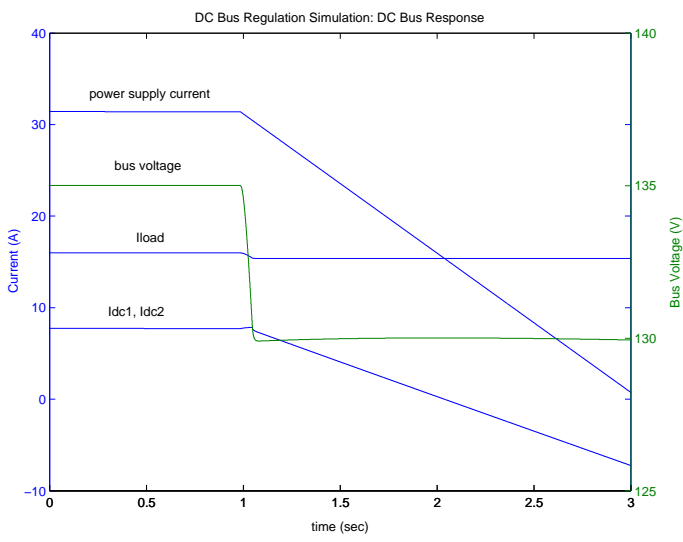

FIGURE 6- DC BUS RESPONSE DURING REGULATION

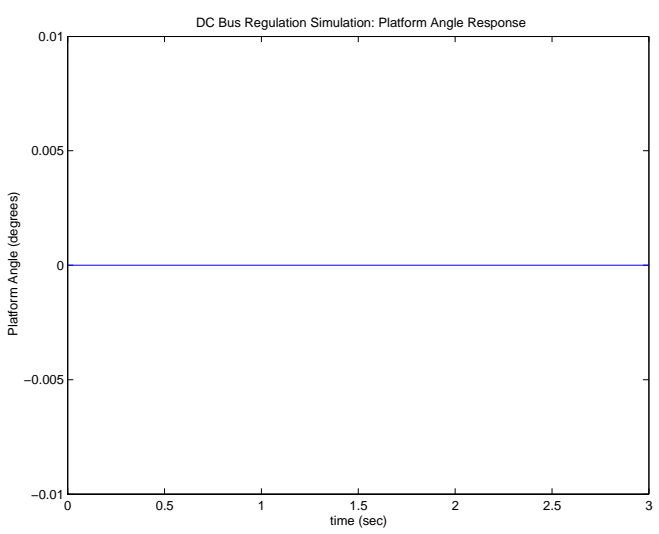

FIGURE 7- PLATFORM ANGLE DURING DC BUS REGULATION 
to the flywheel system voltage regulation set point value. This setpoint, $V_{D C}^{*}$, is 130 volts but due to the large capacitor in the model it takes approximately 0.1 seconds for the system to reach its final value.

The system transitions from charge reduction to discharge mode when the power supply current can no longer meet the load current requirements and $I_{D C I}$ and $I_{D C 2}$ swing negative. At this point, the flywheels are discharging; current from the flywheels is required to meet the needs of the load. In this mode, the flywheel system is still maintaining DC bus regulation. In this simulation, this transition occurs at about two seconds. In the modes when the flywheel regulates the $\mathrm{DC}$ bus the voltage is held within 0.1 volts of the setpoint.

Figure 7 displays the platform angle change during the mode transitions. There is no change in the commanded or actual platform angle during the mode transitions.

\section{Angle Regulation}

The angle regulation simulation examines platform angle and bus voltage regulation as the system responds to a step change in commanded platform angle. This represents a commanded spacecraft direction change. For this simulation, the

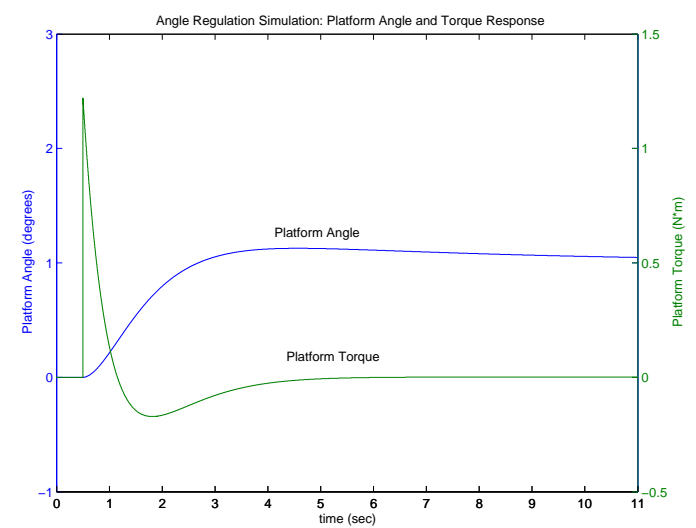

FIGURE 8- PLATFORM RESPONSE DURING ANGLE REGULATION

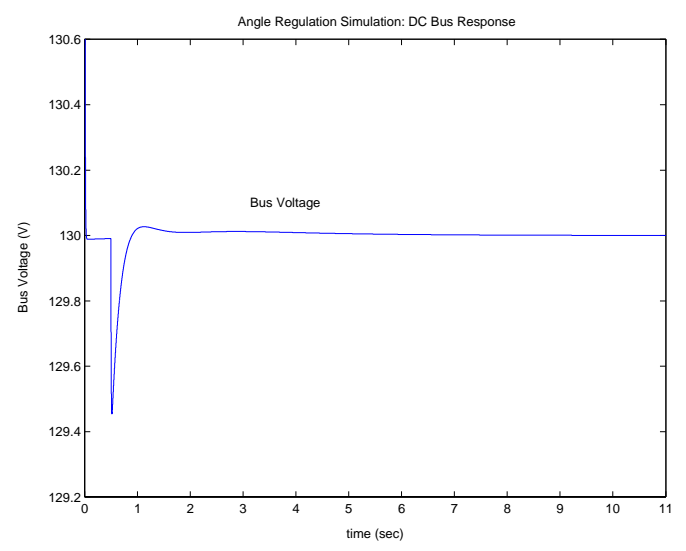

FIGURE 9- DC BUS DURING ANGLE REGULATION system is in discharge mode, with a minimal electrical load. Simulation parameters are summarized in row 2 of Table 2.

The attitude regulator (see Fig. 3 ) is a simple PID, with gains set heuristically to limit the flywheel motor currents to $30 \mathrm{~A}$. In this simulation, a one degree step change is made in theta ${ }^{*}$, which is the angle commanded into the attitude regulator. The results are summarized in Figure 8 . Note that the angle settles to the set point and the torque settles back to zero within a few seconds; this represents satisfactory response to a step change in commanded angle.

The bus regulation during this step change in angle is displayed in Figure 9. Since the system is in discharge mode, all of the current for the load is provided by the flywheel system. In deriving equation (11), it is assumed that the q-axis rotor reference frame current, $i_{q s}^{r}$, is in steady state; however, with a step change in angle, the $q$-axis current jumps abruptly, causing some error in the DC current. There is a brief spike in the $I_{D C}$ current, and a resultant dip in bus voltage. Note that the system responds very quickly to the error; the bus voltage is regulated to within 0.5 volt of the commanded value, which is less than $0.5 \%$ of the nominal bus voltage setpoint.

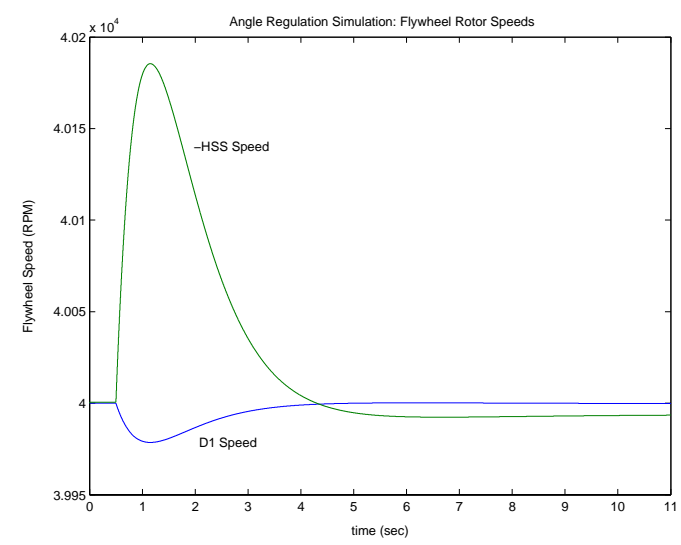

FIGURE 10- FLYWHEEL SPEEDS DURING ANGLE REGULATION

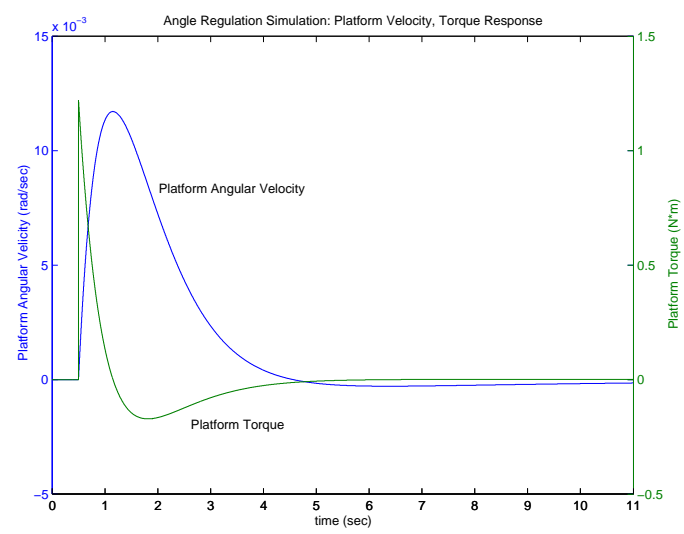

FIGURE 11- PLATFORM SPEED DURING ANGLE REGULATION 
A physical understanding of the dynamics of the platform motion can be achieved by examining the flywheel speeds and the platform torque and angular velocity during the step change. A plot of the speeds of the two flywheels during the step in commanded angle is shown in Figure $10 . \quad$ In this plot, the HSS flywheel speed is plotted as the negative of its actual speed, so the two speeds can be observed on the same plot. The same torque command results in a greater speed change in the HSS as compared to D1 due to the differences in the flywheels' inertia. From about 0.5 to 1.3 seconds, the HSS flywheel accelerates in the negative speed direction and the D1 flywheel decelerates, generating a positive platform torque and a positive angular velocity of the platform. After 1.3 seconds, the flywheel accelerations change direction, exerting a net negative torque on the platform, slowing it down as it reaches the position setpoint.

Figure 11 shows the corresponding platform angular velocity and the total torque, $T_{p}$.

\section{Torque Disturbance Rejection}

The final simulation demonstrates the disturbance rejection capability of the controller. A step change in torque is applied to the platform dynamics (the " $T_{d}$ " input to the "1DOF Platform Plant Model" of Fig. 3) and the capability of the controller to maintain the platform angle at the setpoint is studied. The system is in discharge mode, with a minimal electrical load. Simulation parameters are summarized in row 3 of Table 2. This represents a physical disturbance to the spacecraft.

The applied torque disturbance is $0.05 \mathrm{~N}^{*} \mathrm{~m}$ which is about $10 \%$ of the maximum torque capability of either flywheel. Figure 12 shows the application of the torque disturbance at 0.5 seconds. The sum of the torque on the platform thus jumps from zero to $0.05 \mathrm{~N}^{*} \mathrm{~m}$ at 0.5 seconds. This causes the platform to begin to rotate away from its setpoint of 0 degrees. The resulting position error is acted upon by the PID in the attitude regulator block (figure 3 ) and creates the appropriate current commands, $I^{*_{r}}{ }_{q s l}$ and $I^{*_{r}}{ }_{q s 2}$, to the flywheels as shown in Fig. 13. This results in a net torque applied to the platform to counteract the disturbance torque and reduce the position error as shown in Fig. 12.

Figure 14 shows the speed of each of the flywheels as the disturbance torque is rejected and the platform position is returned to its original position.

\section{CONCLUSIONS}

This paper presents the simulation results of a combined flywheel energy storage system and a single axis attitude control system. The simulation demonstrates that it is possible to use two flywheels to simultaneously provide energy storage for the electrical system while regulating the spacecraft platform attitude in a single axis. A new control algorithm was developed which uses the platform angle requirement and the electrical system power requirement to determine the appropriate current

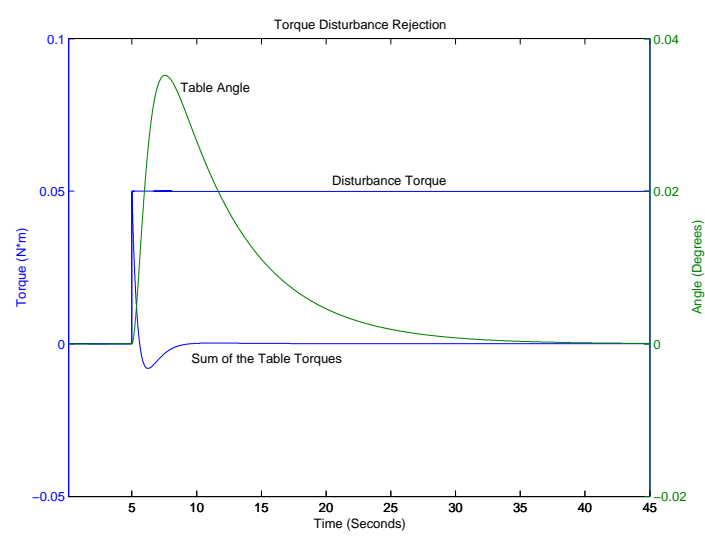

FIGURE 12- PLATFORM DURING TORQUE DISTURBANCE REJECTION

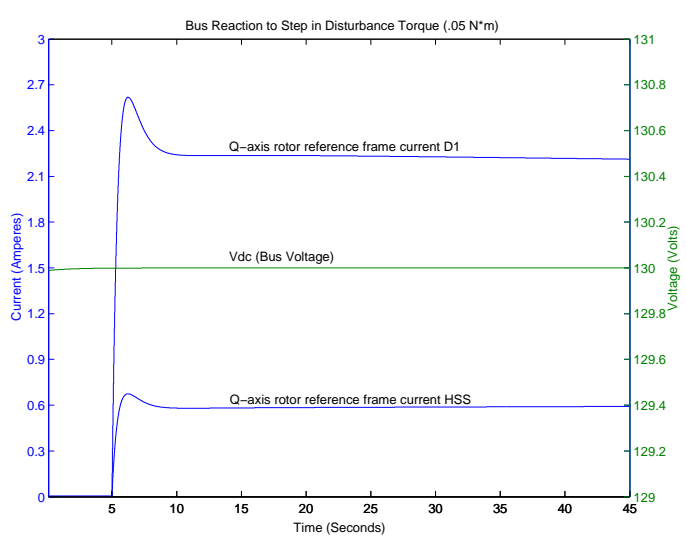

FIGURE 13- DC BUS DURING TORQUE DISTURBANCE REJECTION

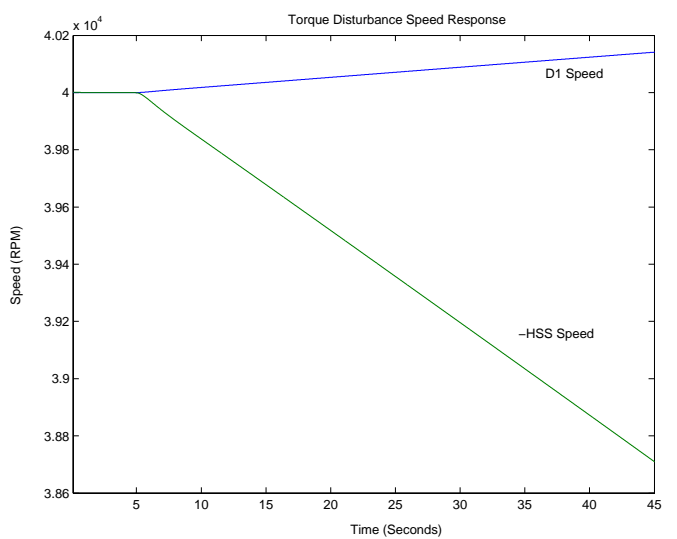

FIGURE 14- FLYWHEEL SPEEDS DURING TORQUE DISTURBANCE REJECTION

commands to the two flywheel motor controllers. A complete system model was developed to test the new controller in simulation. The model includes both the electrical and mechanical components: the flywheel motor/generator units and their control, the DC bus and the electrical load, the platform inertial model and the new control algorithm. Simulation results show that the new controller can successfully maintain commanded platform angle through all mode 
transitions, and can regulate the DC bus voltage under charge reduction and discharge conditions while maintaining the correct platform angle. In addition, a step change in platform angle can be achieved with minimal impact (less than $0.5 \%$ ) on the DC bus voltage. The system also can reject step torque disturbances.

Future work includes demonstrating this control algorithm experimentally using two flywheel units, an air table and an electrical load. Additionally, more work will be done to optimize the controller to achieve the best possible overall system response.

This work is a first step toward an overall program which will ultimately reduce the cost and mass of future space vehicles with the combination of the energy storage and the attitude control systems.

\section{REFERENCES}

Kascak, P. E. et al., 2001, "International Space Station Bus Regulation With NASA Glenn Research Center Flywheel Energy Storage System Development Unit," NASA/TM-2001-211138, NASA Glenn Research Center, Cleveland, $\mathrm{OH}$.
Kenny, B. H. et al., 2001, "Advanced Motor Control Test Facility for NASA GRC Flywheel Energy Storage System Technology Development Unit," NASA/TM-2001-210986, NASA Glenn Research Center, Cleveland, $\mathrm{OH}$.

Krishnan, R., Permanent Magnet Synchronous and Brushless DC Motor Drives: Theory, Operation, Performance, Modeling, Simulation, Analysis and Design, Virginia Tech., Blacksburg, Virginia, 1999.

McLallin, K. L. et al., 2001, "Aerospace Flywheel Technology Development for IPACS Applications," NASA/TM-2001-211093, NASA Glenn Research Center, Cleveland, $\mathrm{OH}$.

Meriam, Kraige, Engineering Mechanics Dynamics $2^{\text {nd }}$ Edition, University of California Santa Barbara, California, 1986.

Novotny, D. W. and T. A. Lipo, Vector Control and Dynamics of AC Drives, Oxford Science Publications, Oxford, 1996.

Trase, L., "The Evaluation and Implementation of a Water Containment System to Support Aerospace Flywheel Testing," to be published at 2002 IECEC, Washington, DC. 


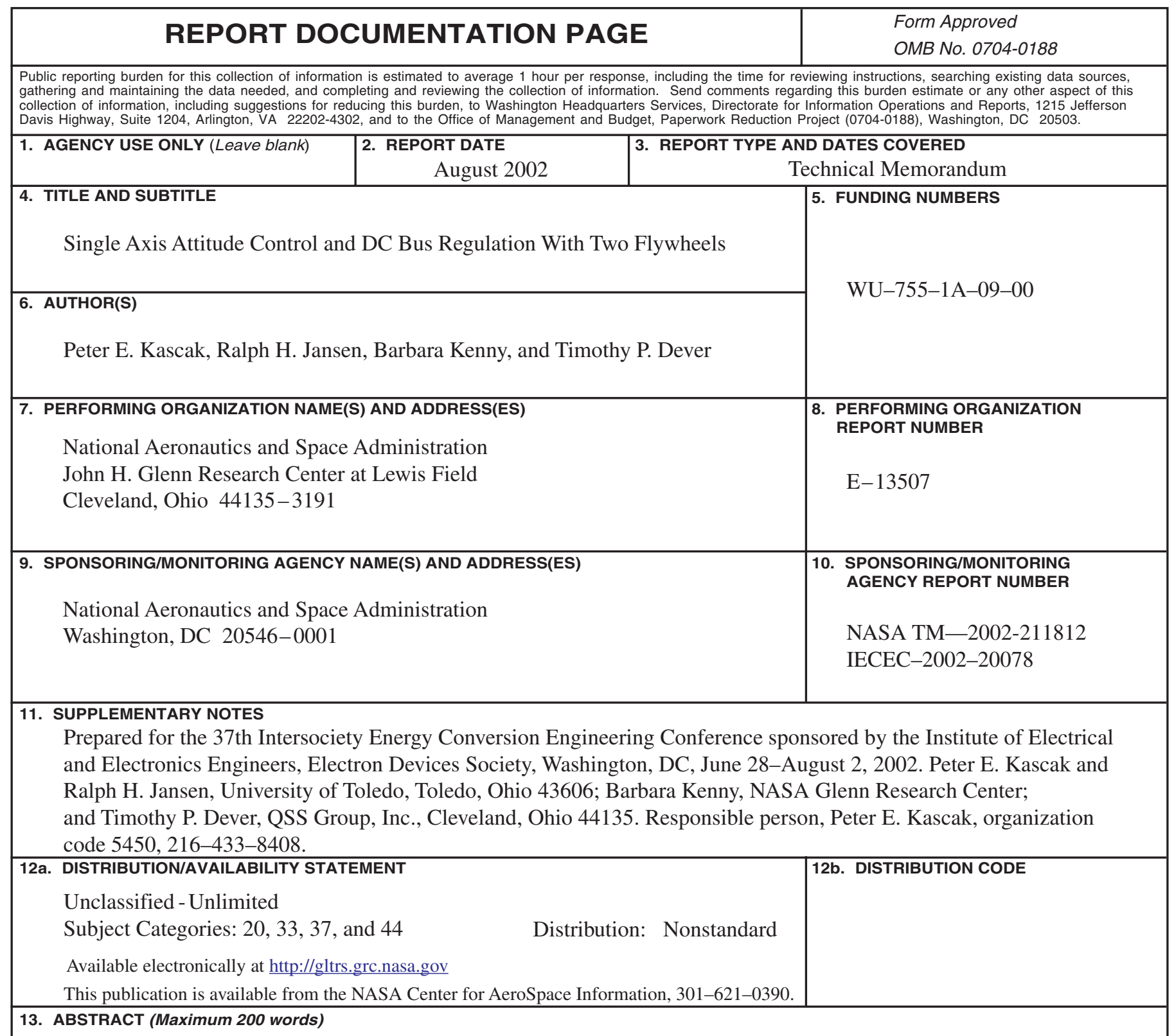

A computer simulation of a flywheel energy storage single axis attitude control system is described. The simulation models hardware which will be experimentally tested in the future. This hardware consists of two counter rotating flywheels mounted to an airtable. The airtable allows one axis of rotational motion. An inertia DC bus coordinator is set forth that allows the two control problems, bus regulation and attitude control, to be separated. Simulation results are presented with a previously derived flywheel bus regulator and a simple PID attitude controller.

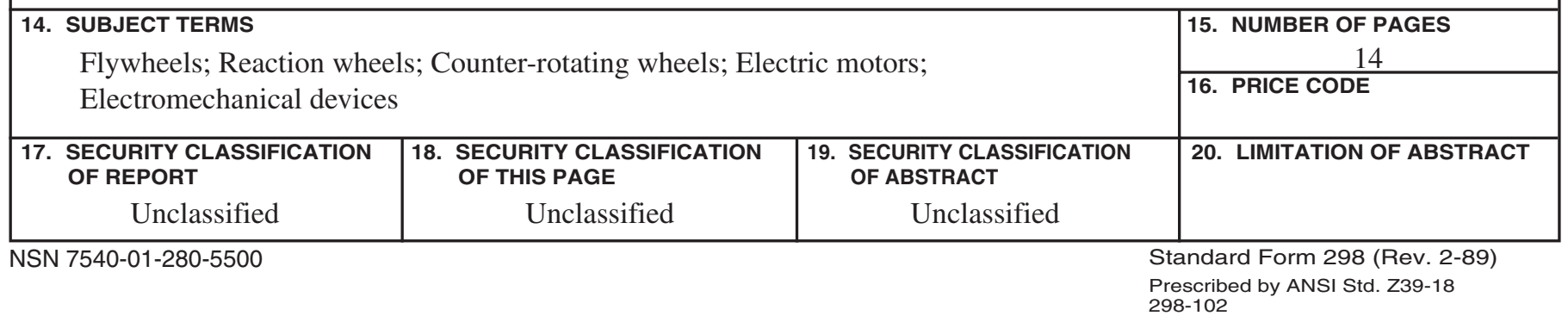



